\title{
Secondary Transfer of Semen
}

\section{Mette Pagh Schou*}

Department of Forensic Medicine, University of Southern Denmark, Odense C, Denmark

*Corresponding author: Mette Pagh Schou, University of Southern Denmark, Institute of Forensic Medicine, J.B. Winsløws Vej 17B, Odense C, DK-5000, Denmark, Tel: +45 40547873; FAX: +45 65916227; E-mail: mschou@health.sdu.dk

Rec date: Sep 6, 2014, Acc date: Oct 22, 2014, Pub date: Oct 26, 2014

Copyright: (C) 2014 Schou MP. This is an open-access article distributed under the terms of the Creative Commons Attribution License, which permits unrestricted use, distribution, and reproduction in any medium, provided the original author and source are credited.

\begin{abstract}
A case is described of a three year old girl who had been treated for urinary tract infections during a longer period. At one incident erythrocytes and spermatozoa were found in the girl's urine. The mother explained that she had intercourse with her husband early in the morning, and that she used a menstrual cup. As she was emptying the cup during toilet visit with the girl, she had blood on her fingers. When the girl urinated, the urine also touched the mother's fingers thus washing some of the blood including spermatozoa from the intercourse down into the urine sample. The forensic examination, including DNA-profiling of blood and semen, did not contradict this explanation. No other possible cause was found for this contamination with erythrocytes and semen in the girl's urine. Child abuse was highly unlikely.
\end{abstract}

\section{Introduction}

The interpretation of forensic findings is not always easy as demonstrated in this case of suspected sexual abuse of a three year old girl. The finding of spermatozoa and blood in the urine of a three year old girl will normally raise suspicion of sexual abuse. However, there may be alternative explanations, as demonstrated in this case report.

In the case report the reader will learn about the 'Lady Cup', Which is a devise not well known. The menstrual cup (Lady Cup) is a bellshaped cup made of soft silicone. It is placed in the vagina for the collection of menstrual blood and is re-used as it is taken out, emptied and reinstalled in connection with toilet visits [1] (Figure 1).

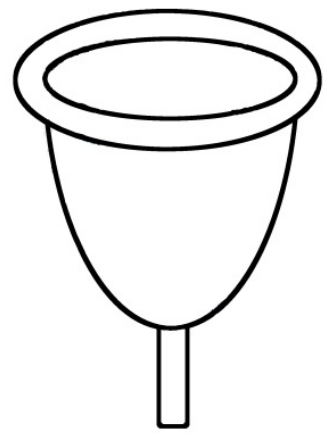

Figure 1: The Lady Cup

\section{Case Report}

The Institute of Forensic Medicine was requested to perform an immediate examination of a three year old girl as there was suspicion of sexual assault. The girl had over a longer period of time been treated for infections in the urinary tract. At the hospital they were not able to find any physical underlying cause for the infections. The day before the forensic examination her mother had taken contact to the pediatric department as the girl now again showed symptoms of urinary tract infection. The mother handed a urine sample from the daughter over to the department for further examination.

At microscopy of the urine sample there were found erythrocytes and spermatozoa (Figure 2). The girl and her mother were readmitted to hospital for another urine sample. This time neither blood nor spermatozoa were detected. The mother was shocked at the finding of spermatozoa in her daughter's urine and was initially not able to explain their presence. At a later stage she explained that she and her daughter both had taken a bath earlier that day. The mother had her menstrual period at the time with much bleeding. After the bath, she and the daughter wiped themselves with the same towel. Late on the night before she had intercourse with her husband, and he ejaculated in her vagina. The mother had mentioned this as a possible explanation to the staff at the hospital. They did not find it possible and suspected that the girl had been a victim of sexual abuse and reported it to the police.

The forensic examination of the girl was performed the day after the finding of spermatozoa in her urine.

The mother was present during the examination, and she gave a new explanation. She explained that when sampling the urine, she had first used the toilet and thereafter collected urine from the daughter. She confirmed that she and her husband had had intercourse without a condom shortly before collection of the urine. She had very strong menstruations and used a "menstrual cup".

The mother had emptied the cup during the toilet visit, but as the daughter suddenly felt an urge to urinate, the mother did not have time to wash her hands and she explained that the daughter had urinated on her hand when she collected the urine. The daughter's urine was thus mixed with menstruation blood from the mother's hand. 
Page 2 of 3

The girl was found to be normal in every respect; there were no signs of trauma on body or genitals. Samples were taken from the vaginal opening and the skin of the labia for microscopy and DNAprofiling, and the urine samples with the spermatozoa were secured for further examination. By direct microscopy of smears from the vaginal opening, the anal opening and the perineum, no spermatozoa were found. By microscopy of the urine sample collected at the hospital it was confirmed that there were numerous spermatozoa whereof many with remaining tails (Figure 2).

The forensic genetic analysis was compatible with the explanation from the mother, as the material from the vaginal opening could only have come from the girl herself and not from either the mother or the father. In the urine sample human blood and semen were detected. In the sperm cell fraction DNA from a male was detected and in the cell fraction a larger amount of DNA from a female person. The DNAprofile of the sperm cell fraction was convincingly that of the father and the DNA-profile of the larger amount of DNA from the remaining cell fraction was convincingly from the mother.

An employee from the social services was called in, waiting outside the examination room. She was there to remove the girl from the parents if after the examination there were any suspicion of sexual abuse.

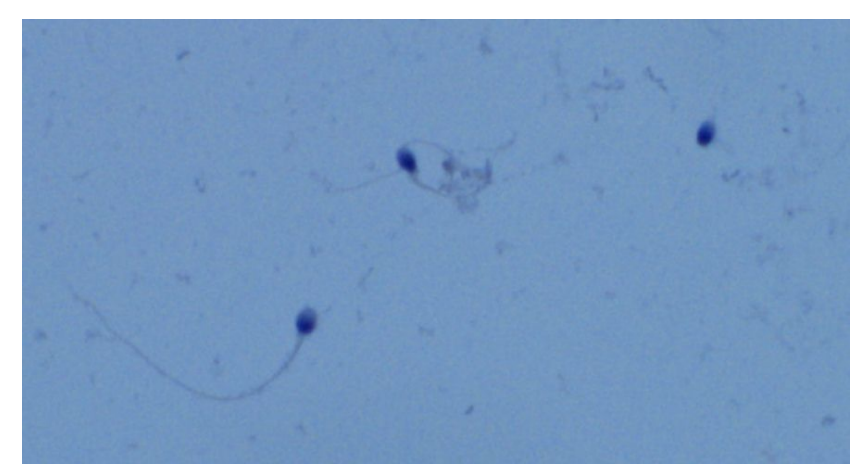

Figure 2: Smear of urine with spermatozoa

\section{Discussion}

This is an interesting case, where the suspicion of sexual abuse was high in the beginning, but as the mother explained the circumstances surrounding the collection of the daughter's urine, the case became less suspicious.

The first explanation from the mother stated that she and her daughter had shared a towel after a bath a few hours before collecting the urine sample. She thought that the blood and semen from her vagina could have transferred to the towel and then from the towel to the daughter's genitals. Goray et al [2] performed a study of secondary DNA transfer. The study showed that wet samples such as blood or semen were much more likely to be transferred from one surface/ substrate to another. It also showed that there were minimal transfer rates of DNA with wet samples and absorbent substrates, such as cotton or wool. The highest transfer rates were found with wet samples from a non-absorbent primary substrate, such as plastic, to an absorbent secondary surface. In this case the towel must be categorized as an absorbent substrate and thus only minimal transfer is likely. Wiegand et al [3] also performed a study of secondary transfer of biological material from different surfaces and found that only in rare instances of secondary transfer were DNA concentrations high enough for complete DNA profiles. All were transfers from stains on plastic. We found the mother's first explanation highly unlikely and she also changed it to a more likely but yet unusual version.

Before the forensic examination various scenarios were considered; 1) the girl could have been sexually abused with ejaculation inside or outside of her genitals. This might or might not have caused visible damage. Adams et al. [4] and Grossin et al. [5] stated that there were no injuries found during forensic examination in the majority of cases of sexually abused children. Although we did not find any genital injuries in this case, we could not totally exclude sexual abuse because of this alone. But the presence of spermatozoa and blood in the urine sample indicates a short time from the possible abuse until the examination, which is correlated to a higher incidence of abnormal genital findings according to Adams et al. [4]. Astrup et al. [6] found spermatozoa present in the external genitalia as long as 50 hours post coitus. We can conclude that if, in this case, there had been ejaculation inside the vagina of the girl we most likely would have found spermatozoa on the external genitalia during the forensic examination.

2) The mother's explanation on how her menstrual blood and the semen of the father ended up in the girl's urine by the sharing of a towel immediately after the bath was elaborated by the mother during the forensic examination and supported by the forensic genetic analysis. The mother explained that she and her daughter had been alone together all morning for several hours until the urine sample was taken. The father had gone to work early that morning and had not been alone with the girl. The parents were interviewed both by the police and by the examining doctors and were found to be sincerely concerned about the girl and her wellbeing. The police found no evidence of any type of abuse and we found the mother's explanation likely and excluded the possibility of sexual abuse. The social services will however focus on the family and the girl's wellbeing in the future.

\section{Conclusion}

The conclusion in this case must be: One has to consider all possibilities, when interpreting findings during a forensic examination. Sometimes explanations, that were not previously considered, will surface and sometimes even unthinkable explanations might emerge.

\section{Acknowledgement}

The author is grateful to consultant Jørgen Gram, Department of Clinical Biochemistry in Esbjerg, for his careful observations.

\section{References}

1. Stewart K, Powell M, Greer R (2009) An alternative to conventional sanitary protection: would women use a menstrual cup? J Obstet Gynaecol 29: 49-52.

2. Goray M, Eken E, Mitchell RJ, van Oorschot RA (2010) Secondary DNA transfer of biological substances under varying test conditions. Forensic Sci Int Genet 4: 62-67.

3. Wiegand P, Heimbold C, Klein R, Immel U, Stiller D, et al. (2011) Transfer of biological stains from different surfaces. Int J Legal Med 125: 727-731.

4. Adams JA, Harper K, Knudson S, Revilla J (1994) Examination findings in legally confirmed child sexual abuse: it's normal to be normal. Pediatrics 94: 310-317. 
Citation: Schou MP (2014) Secondary Transfer of Semen. J Forensic Res 5: 1000250. doi:10.4172/2157-7145.1000250

Page 3 of 3

5. Grossin C, Sibille I, Lorin de la Grandmaison G, Banasr A, Brion F, et al. (2003) Analysis of 418 cases of sexual assault. Forensic Sci Int 131: 125-130.
6. Astrup BS, Thomsen JL, Lauritsen J, Ravn P (2012) Detection of spermatozoa following consensual sexual intercourse. Forensic Sci Int 221: 137-141. 